\title{
Imanência e transcendência em Franz Rosenzweig - contribuições da Filosofia da Religião para as Ciências da Saúde
}

\begin{abstract}
Viviane Cristina Cândido*
\section{Resumo}

Franz Rosenzweig evidencia como a filosofia retira Homem, Mundo e Deus da contingência, lançando-os ou para a super valorização de suas individualidades ou para a abstração. Em seu novo pensamento aponta que estas potências somente podem ser conhecidas em suas realidades efetivas, no tempo e nas relações, assim, os conceitos de imanência e transcendência não são estáticos. Neste artigo, apresentamos os principais pontos deste novo pensamento e como inclui a experiência religiosa, ensaiando uma compreensão da filosofia da religião. De um ponto de vista pragmático, como pode fundamentar uma filosofia das ciências da saúde e, consequentemente, a espiritualidade no cuidado e na assistência em saúde.
\end{abstract}

Palavras-chave: Filosofia; Franz Rosenzweig; Novo Pensamento; Ciências da Saúde; Espiritualidade e Saúde.

\section{Immanence and transcendence in Franz Rosenzweig - contributions from Philosophy of Religion to Health Sciences}

\section{Abstract}

Franz Rosenzweig shows how philosophy removes Man, World and God from contingency, casting them either to the overvaluation of their individualities or to abstraction. In his new thinking he points out that these powers can only be known within their effective realities, in time and in relationships, therefore, the concepts of immanence and transcendence are not static. In this article, we present the main points of this new thinking and how it includes the religious experience, essaying an understanding of the philosophy of religion. From a pragmatic point of view, how can it substantiate a philosophy of health sciences and, consequently, spirituality in health care and assistance.

Key words: Philosophy; Franz Rosenzweig; New thinking; Health Sciences; Spirituality and Health.

* Doutora em Ciências da Religião pela PUCSP, mestra em Educação, graduada em Filosofia e Pedagogia. Docente e pesquisadora da UNIFESP - Escola Paulista de Medicina. Coordenadora do Grupo de Estudos de Filosofia da Saúde UNIFESP - CNPq. 


\section{Inmanencia y trascendencia en Franz Rosenzweig - contribuciones de la filosofía de la religión a las ciencias de la salud}

\section{Resumen}

Franz Rosenzweig enseña cómo la filosofía saca al hombre, al mundo y a Dios de la contingencia, lanzándolos a la sobrevaloración de sus individualidades o a la abstracción. En su nuevo pensamiento, señala que estos poderes solo pueden conocerse en sus realidades efectivas, en el tiempo y en las relaciones, por lo que los conceptos de inmanencia y trascendencia no son estáticos. En este artículo, presentamos los puntos principales de este nuevo pensamiento y cómo él incluye la experiencia religiosa, ensayando una comprensión de la filosofía de la religión. Desde un punto de vista pragmático, cómo ella puede fundar una filosofía de las ciencias de la salud y, en consecuencia, la espiritualidad en la atención y asistencia sanitaria.

Palabras clave: Filosofía; Franz Rosenzweig; Nuevo Pensamiento; Ciencias de la Salud; Espiritualidad y Salud.

\section{Introdução}

Num primeiro olhar, poderíamos afirmar que a modernidade pouco quer saber de transcendência e, menos ainda do transcendente, talvez porque uma das características fundamentais desse tempo/espaço seja ter o Homem como centro, a partir do qual se posicionam o Mundo e Deus. Esse Homem autocentrado acredita que é autossuficiente, não depende de nada e nem de ninguém, está no controle de sua vida, das outras pessoas e do Mundo e, em algumas situações, consegue ocupar até mesmo o lugar de Deus, exercendo o papel de criador, tal qual o Frankenstein de Mary Shelley.

Assim, transcender, no sentido de sair de si em direção a um outro, não é necessário, pelo contrário, é pouco desejável, dado o conforto que esse lugar - o de ser um si mesmo - representa, do que decorre a existência de um transcendente significar, inclusive, uma ameaça à soberania e autonomia do eu.

Todavia, a tranquilidade dessa posição se vê ameaçada quando o Homem É, ou seja, quando se lhe acontece esbarrar com a sua condição como ser mortal num cenário de doença pessoal ou na doença ou morte de um ente querido, por exemplo. Nesse lugar alteram-se as perspectivas e onde havia autossuficiência passa a existir dependência, onde havia controle da vida passa a existir a experiência de viver um dia de cada vez e cada um como se fosse o último e, finalmente, onde existia um "criador" evidenciase uma criatura, ciente da impossibilidade de prever o tempo e prover as condições de sua existência. 
Imanência e transcendência em Franz Rosenžweig - 153 contribuições da Filosofia da Religião para as Ciências da Saúde

Essa profunda, e não menos dolorosa, mudança acontece exponencialmente naquelas situações em que a vida corre risco, do que decorre podermos afirmar que se existe um lugar onde a relação entre o ser humano e a transcendência acontece, esse é exatamente o lugar da falta, da ausência da saúde, quando a dor e o sofrimento, causados pela doença e pela percepção concreta de nossa humanidade - caracterizada pela certeza da morte - se instalam e se sobrepõe o doloroso sentimento de impotência frente a essa inevitável experiência.

Do ponto de vista especulativo, tem nos ocupado a especificidade de uma Filosofia das Ciências da Saúde capaz de fornecer fundamentos para o pensar acerca de conceitos caros a essa área como, por exemplo, saúde, doença, cura, dor, sofrimento e morte, os quais carecem de uma base epistemológica que tome em conta a nossa condição - a humana. Considerando que a percepção clara dessa condição se dá exatamente nas ações em cuidado e assistência em saúde, onde a dor, o sofrimento e a morte passam a ocupar uma posição privilegiada, exigindo de nós reflexões e ações que possam lançar luzes a situações que parecem intransponíveis, bem como contribuir para uma experiência em que o ser vivente não se despedace, deixamos de lado a especulação para assumir o pragmático, o lugar em que aquilo que pensamos necessita orientar o nosso fazer.

Diante da doença e da morte; da experiencia da fragilidade e da vulnerabilidade têm lugar as experiências ligadas à espiritualidade, motivo pelo qual necessitamos de um pensamento não excludente, que considere todas as contingências que nos tornam exatamente quem somos.

Queremos apresentar nossa experiência de revisita ao filósofo Franz Rosenzweig (1886-1929). Quando o conhecemos e estudamos, há 15 anos, o fizemos do lugar da Educação (2010), da Literatura (2011) e da Espiritualidade (2012), mais recentemente, vimos considerando-o para aportar uma Filosofia das Ciências da Saúde em geral e, mais especificamente a reflexão/ação no binômio Espiritualidade e Saúde recorrendo também à Filosofia da Religião. É ilustrativo destacar a obra conhecida como O Livrinho em duas de suas traduções El libro del sentido común sano y enfermo (2001) ou Understanding The Sick \& The Healthy - A View of World, Man, and God (1999) ${ }^{1}$, uma metáfora

Consideraremos para as referências as traduções espanholas das três principais obras de Franz Rosenzweig aqui citadas. As traduções, tanto das referências em espanhol, quanto daquelas em inglês são de responsabilidade da autora, posto que, com exceção da obra Hegel e o Estado, não há traduções de sua obra para o português. 
acerca de um filósofo diagnosticado com uma paralisia, resultante de seus esforços em buscar a essência das coisas; seu tratamento e cura.

Pierre Bouretz, tratando do tema Filosofia e Messianismo, assim inicia a apresentação de mais uma das testemunhas do futuro "A experiência filosófica de Franz Rosenzweig parece de tal maneira imbricada na trama histórica de sua época e na carne de quem a viveu que é, à primeira vista, quase impossível dissociá-las." (2011, p. 149).

O filósofo, teólogo e tradutor Rosenzweig teve uma vasta formação que incluiu a Literatura, a Filosofia, a História, a Medicina, além de Línguas como o árabe. Sua tese de doutorado, Hegel e o Estado (2008), sinalizava o caminho do filósofo rumo a um novo pensamento, como ele mesmo viria a apresentar sua filosofia, e já apontava uma desconfiança acerca do idealismo alemão, uma filosofia que conduzia à compreensão abstrata do ser humano, distanciando-o da sua realidade mesma.

Essa desconfiança se confirmou quando o homem Rosenzweig se viu atuando como enfermeiro na Cruz Vermelha, posteriormente, nas trincheiras da Primeira Grande Guerra e, nos últimos meses desta, também doente com quadros de gripe, pneumonia e malária. É desse lugar, do contato com seres humanos reais, seus enfrentamentos e, não raro, suas mortes e de sua própria experiência de fragilidade, que escreve sua principal obra $A$ Estrela da Redenção (2006), enviada em fragmentos nas cartas para sua mãe.

Escrevendo em condições tanto desfavoráveis para o pensador, quanto significativas para o homem, Rosenzweig reconhece a realidade, a experiência e o fato de que o novo pensamento nasce daí e não das abstrações e idealizações propostas pelo antigo pensamento, na história do pensamento filosófico desde Tales até Hegel. A ele interessa o ser humano real atingível somente pela experiência. Não é sem motivo que Walter Benjamin (1892-1940), no ano da morte do autor, afirmou que $A$ Estrela da Redenção era "uma das pouquíssimas obras que ainda valiam a pena serem lidas".

A fim de entendermos o peso desta consideração, lembramos seu famoso texto, O Narrador, no qual aponta Nikolai Leskov como o maior e um dos últimos narradores russos, dada sua capacidade de trazer a alma russa em seus contos. Benjamin valoriza a experiência, que passa de pessoa a pessoa, como fonte para a narrativa e aponta que "no final da guerra, observou-se que os combatentes voltavam mudos do campo de batalha não mais ricos, e sim mais pobres em experiência comunicável. (1985, p. 198). 
Franz Rosenzweig não emudeceu, ao contrário, vivenciando a dura experiência do front, organizou seu sistema filosófico considerando a contingência - somos seres marcados por condições que afetam nossa existência; a temporalidade; a diferença, porque somos contingentes, sendo o outro eminentemente outro, e, consequentemente, a perspectiva dialógica como caminhos de acesso ao real, já que o outro é um outro exatamente porque fala "Esse alguém é sempre um alguém inteiramente determinado e, diferentemente do público em geral, não tem meramente orelhas, e sim também boca." (2005, p. 35).

No espaço desse artigo, pretendemos apresentar a filosofia experimentada de Franz Rosenzweig, centrada nas relações e na temporalidade que, justamente por isso, conduz a uma compreensão diferenciada dos conceitos de imanência e transcendência; refletir acerca da presença de uma Filosofia da Religião em seu pensamento e, numa perspectiva mais pragmática, acerca das possibilidades desse novo pensamento no campo das Ciências da Saúde em geral e, mais especificamente, no cuidado e na assistência, nas questões acerca da espiritualidade e saúde.

\section{A Filosofia Experimentada de Franz Rosenzweig}

Num olhar retrospectivo, Rosenzweig identifica Mundo, Homem e Deus como os três conceitos fundamentais do pensamento filosófico sobre os quais se debruçaram os filósofos de Tales a Hegel. As experiências vividas na Primeira Grande Guerra, somadas àquelas relativas ao seu pertencimento religioso e à convivência com a doença que o levou à morte, a esclerose lateral amiotrófica, reforçaram nele algumas de suas inquietações acerca da filosofia sistemática produzida até então, no que concerne ao idealismo, fruto da busca pela essência que tira do fluxo da vida aquilo que deseja conhecer; à imanência e à transcendência; à desconsideração do tempo e da morte e à compreensão da totalidade em detrimento da multiplicidade com a consequente anulação das diferenças.

Essa ênfase na empiria, tão característica do pensamento de Rosenzweig, é bem apontada por Reyes Mate ao analisar seu Novo Pensamento e constatar que não há justificação teórica para as três realidades originárias Mundo, Homem e Deus serem estas e não outras, e afirma: “A justificação é empírica: qualquer um que recorra à racionalidade ocidental, desde os Jônicos até Jena, constatará que esses são os temas da tradição ocidental. A filosofia não cessa de refletir sobre esses três tópicos." (MATE, 2006, p. 418). 
Para Rosenzweig, a busca pela essência paralisa porque retira aquilo que se pretende conhecer do curso da vida e do tempo, transformando-o em objeto. Trata-se da confusão das essencialidades com as realidades efetivas de Mundo, Homem e Deus que, tratados como essência, são conceitos universais, o que para ele, é inconcebível, pois isso significa retirar esses três elementos do fluxo da vida, o que não responde à contingência que está na realidade das coisas e dada pelos seus nomes.

O autor apresenta o resultado dessa negação da relação entre as três potências e da consideração estrita de suas essências no primeiro volume da Estrela, afirmando que o Mundo considerado pela filosofia como essencialmente lógico, diante da impossibilidade de, com isso, responder às questões da vida, passa a ser designado metalógico, o Homem considerado pela filosofia como essencialmente ético, diante da impossibilidade de, com isso, responder às questões da vida, passa a ser designado metaético e Deus considerado pela filosofia como essencialmente Physis, diante da impossibilidade de, com isso, responder às questões da vida, passa a ser designado metafísico.

Para ele, a realidade é inalcançável somente pela razão como a entendemos. A partir das relações e considerando aquilo que faz com que o Mundo e o Homem sejam quem são é que podemos conhecê-los e entender a sua relação com Deus. Enquanto o antigo pensamento isolava esses três elementos, com a super valorização de suas individualidades; o novo pensamento pretende fugir à abstração, a que está fadado todo aquele que é retirado da contingência, entendida como Barbara Smith, para quem afirmar que algo é contingente significa dizer que é "produto de condições (experienciais, contextuais, institucionais, e assim por diante) que são fundamentalmente variáveis e sempre até certo ponto imprevisíveis e incontroláveis.” (2002, p. 18).

Questionando a possibilidade de conhecer o todo, Rosenzweig aponta para a singularidade, os limites, a insuficiência, a nossa condição como seres mortais, parte de nossa contingência, a qual, necessariamente devemos ter em conta se quisermos, de fato, nos aproximar da realidade.

Desta forma, a contingência do homem está em assumir-se como criatura e isso significa, para além de uma categoria religiosa que o designaria como filho de Deus, assumir os limites próprios do humano e não cair na tentação de pretender-se Deus, consciente de ser mortal; a contingência do mundo está em sua criaturalidade, ou seja, está sendo criado, não está 
Imanência e transcendência em Franz Rosenžweig - 157 contribuições da Filosofia da Religião para as Ciências da Saúde

pronto ou é fruto, pura e tão somente, de um processo evolutivo cujo final quase podemos pressupor mediados pela ciência; nem da objetividade do pensamento da providência divina, pois não se trata de um mundo para sempre criado.

Do que decorre que Deus não é um ser que intervém no mundo como providência, como milagre ou se oculta por sua vontade, mas é criador e como tal somente pode amar sua criação e com ela se relacionar, é no amor que conhecemos Deus, consequentemente, na relação e na contingência, o que desdobrará na ação. Assim, a existência é em sua realidade efetiva, o que significa que o homem é em sua relação com o outro, o mundo é em sua relação com os homens e Deus é na relação que crentes e não crentes assumem com ele.

A afirmação da relação como condição para o conhecimento desses conceitos, não havendo como conhecê-los em si e sim nas relações que estabelecem entre si, implica numa nova compreensão dos termos imanência e transcendência, colocando-os também em relação, por exemplo, comparando o antigo e o novo pensamento, afirma que "Se, por exemplo, o antigo se propunha a questão se Deus é transcendente ou imanente, o novo procura dizer como e quando Deus passa de estar longe para estar próximo e de estar próximo a estar longe de novo." (ROSENZWEIG, 2005, p. 29). Em outras palavras, considerada a realidade efetiva, temos as relações contingentes e transcendentes entre as três potências.

Trate-se de uma incondicionalidade da relação, consequentemente, de uma oposição ao curso filosófico tradicional, construído sobre a tríade Homem, Mundo e Deus, na qual há sempre a supremacia de um, do qual os outros são deduzidos, na busca pela essência que, por sua vez, "não quer saber nada do tempo". O novo pensamento, ao contrário, considera a existência como experiência no tempo, visto que é nele que ocorre a relação, não se tratando de um ser pensado e sim de um ser pensado no tempo. Como afirmado por Guinsburg, essa distinção radical do pensamento rosenzweiguiano em relação à tradição filosófica diz respeito à existência e como podemos apreendê-la. "No primeiro aspecto, reivindica a revalorização do individual concreto ante o geral abstrato, enquanto, no segundo, e como conseqüência do deslocamento efetuado, a experiência”. (1970, p. 508).

Considerar as relações, significa que somente é possível conhecer no tempo, inclusive as coisas últimas e supremas. "Conhecer a Deus, ao mundo e ao homem significa conhecer o que eles fazem ou o que sucede a eles nos 
tempos da realidade, o que cada um deles faz aos outros e o que acontece a cada um por causa dos outros.” (ROSENZWEIG, 2005, pp. 29 e 32).

Temporalidade significa considerar a morte, Rosenzweig o afirma em seu Livrinho "poder viver quer dizer ter que morrer." A vida pode ser simples quando não se espera escapar da morte, quando se vive sabendo que, ao final, encontraremos a morte, mas não tememos esse encontro. (2001, p. 93). Contudo, o Homem teme a morte e a filosofia deveria ouvir os gritos da humanidade e entender que a morte e a angústia que ela gera não são o nada, são algo. Há muitas mortes, muitos nadas e, justamente, por serem múltiplos, são algo. Não se trata de um nada - único e universal - mas de um nada múltiplo no grito das vítimas da morte no mundo. E a filosofia, antes de ouvir esses gritos pergunta-se sobre o que é o mundo e tem se dedicado durante séculos à disputa entre saber e crer. (2006, pp. 45-46).

A forma de ouvir e responder a esses gritos, nossos próprios, dos outros, do mundo e de Deus é lançar-se na vida, como Rosenzweig nos convida nas linhas que finalizam o texto da Estrela "Para onde se abre essa porta? Você não sabe? Para a vida.” (2006, p. 496).

Esse novo pensamento, que considera as relações no tempo, impõe a necessidade do outro, o qual, como dissemos antes, somente pode ser reconhecido como um outro na sua fala - sua forma de manifestar a si mesmo como um outro diferente de mim. É por isso que Rosenzweig apresentará a narrativa como método em sua Estrela, revelando a importância da linguagem. Pensamos e falamos para alguém que, por sua vez, também pensa e fala, assim a linguagem, a narrativa oportuniza as relações e permite o acesso ao real ao considerar a temporalidade "Precisamente o tempo chega a ser para o narrador inteiramente real. Não o tempo em que algo acontece, e sim o que por si mesmo acontece."

Daí a proposição de um método de falar para superar um antigo pensamento que pretende ser atemporal. "O falar está ligado com o tempo, não quer e nem pode abandonar seu solo nutritivo; não sabe por antecipação até onde se dirige; deixa que o outro lhe dê a base para entrar na conversa." (2005, p. 33).

Em síntese, a Filosofia experimentada de Franz Rosenzweig considera a impossibilidade de conhecer a partir da essência ou da ideia do todo, conhecer só é possível a partir da consideração da experiência que acontece nas relações entre Mundo, Homem e Deus, que pressupõe a singularidade desses elementos, o tempo e, como consequência, a multiplicidade. Experiência, 
Imanência e transcendência em Franz Rosenžweig - 159 contribuições da Filosofia da Religião para as Ciências da Saúde

relação, temporalidade e linguagem são categorias caras a esse novo pensamento porque garantias de acesso ao real.

A consideração do tempo empresta a essa forma de pensar um movimento ocasionado pelos encontros do Mundo, Homem e Deus, do que decorre que imanência e transcendência, por sua vez, deixam de ser categorias estáticas e sim sujeitas aos movimentos de aproximação e distanciamento dos três elementos em suas relações. Além disso, considerar o tempo obriga o pensamento a considerar a morte, o findar do tempo de cada um, como parte de nossa condição - a humana e, consequentemente, expressão do real.

\section{Uma Filosofia que inclui o Homem religioso - De Atenas a Jerusalém}

Em seu livro $O$ novo pensamento - uma forma de resposta aos que leram A Estrela da Redenção e com ele quiseram dialogar, Rosenzweig afirma que esse último "Tampouco tem a pretensão de ser algo como uma filosofia da religião - como poderia sê-lo se nele não aparece em absoluto o termo religião! É antes, meramente um sistema filosófico.” (2005, pp. 14-15). Todavia, afirma Guinsburg que na Alemanha, depois da Primeira Guerra Mundial, se processa um renascimento judaico do qual Franz Rosenzweig, ao lado de Martin Buber e outros, foi um dos maiores incentivadores e um dos principais expoentes (1970, p. 505). Haveria aqui uma contradição?

Guinsburg afirma que, a partir do século XIX, as interpretações do judaísmo conjugavam-se naturalmente, no plano filosófico, com as tendências que caracterizavam o curso da história das ideias. Dessa forma, o pensamento judaico recebia as proposições da filosofia ocidental pós-kirkegaardiana e trabalhada pelo neokantismo, por Nietzsche, pelo bergsonismo e pela fenomenologia e também as críticas às abstrações universalizantes advindas da razão ilustrada, da ideia romântica ou do fato científico, o que aumentava a demanda de uma recuperação filosófica dos valores de uma existência judaica autêntica.

Formado na escola da filosofia idealista alemã, e voltado para as fontes clássicas de Israel, Rosenzweig, por sua vez, era "atraído pelo problema do homem marginal e do judeu na sociedade moderna e inspirado por uma verdadeira procura religiosa" (1970, p. 506).

O que está aqui evidenciado é que Rosenzweig tinha uma experiência como judeu de nascimento, um contato com a produção intelectual judaica em diálogo com a filosofia, pensava a partir dela. Tinha ainda uma experiência 
como judeu religioso, inclusive, por algum tempo, como cristão, portanto, uma forma de pensar, como a que se desenvolve no seio das tradições religiosas que, em virtude da experiência comum, passa a fazer parte do pensamento daqueles que delas participam. Em decorrência disso, seu pensamento trazia categorias ligadas a ambas as experiências.

Voltando à afirmação de Rosenzweig acerca de que a Estrela não tem a pretensão de ser algo como uma filosofia da religião e, ao mesmo tempo considerando o que foi dito por Guinsburg acerca dele, convém destacar que o primeiro buscava explicitar que o trazido pela Estrela não se reduzia a um conteúdo especificamente religioso, como estava sendo compreendido; a compreensão de Filosofia da Religião à qual se refere diz respeito especificamente a esse conteúdo. Na interpretação do segundo podemos encontrar elementos de nossa compreensão da Filosofia da Religião como a investigação da racionalidade advinda da experiência religiosa que, por tornar-se parte da vida da razão de quem a viveu, pode (e para nós deveria) dialogar com a racionalidade como a entendemos filosoficamente.

A Rosenzweig, em coerência com seu sistema filosófico, interessa o Homem religioso e as relações que estabelece com o Mundo, Deus e os outros Homens, sua procura não estava na religião em si, considerando exclusivamente seu aspecto institucional, ao contrário, seu pensamento considerava indistintamente a experiência e, por isso, foi capaz de reler em sua obra as instituições religiosas, islamismo, judaísmo e cristianismo, sobretudo as duas últimas por sua vivência pessoal. Buscava perceber e considerar a experiência humana que nelas acontece, a tal ponto de escolher referir-se ao judeu e ao cristão, entendendo que religioso é o homem.

Para o autor o que estava em evidência eram as relações, configuradas em experiências individuais e coletivas, de crentes e não crentes e, além do mais, inter-relacionadas e com diferentes nuances, do que decorre que se não adentramos na especificidade da experiência religiosa não nos é possível afirmar nada sobre ela.

Considerando o tempo, Rosenzweig apontou o caráter responsivo da religião, que não existe como si mesma. As experiências dos indivíduos, e destes nas instituições, entendidas como formalização estrutural e da prática de uma tradição religiosa, é que se constituem como respostas do Homem - em sua relação com o Mundo - de sua relação com Deus, respostas essas que se dão na vida e é em sua concretude que podem ser analisadas. 
Nesta perspectiva torna-se necessário superar a compreensão meramente institucional da religião e considerar a experiência. Entender a religião do ponto de vista da história das religiões, por exemplo, não dá conta do fato de que as pessoas, de um modo ou de outro, vivem uma experiência religiosa, fazendo, ou não, parte de uma instituição, com diferentes percepções, interações e, até mesmo, negando-as. Além disso, as instituições não existem em si mesmas, e sim porque há indivíduos que delas fazem parte. $\mathrm{O}$ que podemos saber das instituições religiosas, dos indivíduos que creem e que não creem é, simples e puramente, a relação entre eles e o gesto concreto de sua crença ou não crença, individual e coletivamente.

Isto posto, podemos entender que, quando o Judaísmo e o Cristianismo são colocados em evidência por Rosenzweig, na Estrela da Redenção, o que está sendo reconhecido é que existem três conceitos em relação, Mundo, Homem e Deus, e que esta relação segue marcada pelas proposições desses grandes monoteísmos e, ao mesmo tempo, nele são identificadas contribuições importantes para o avanço do pensamento e para a superação de tudo o que impede que Homem e Mundo possam ser mais, no sentido ontológico, justamente pelas possibilidades de transcendência advindas da aproximação entre esses três elementos, os quais, juntos, seguem na imanência, no sentido de estarem presos às suas essências, ao seu ser em si.

Contudo, ao mesmo tempo, reconhece os limites desses monoteísmos, tanto é que aponta o paganismo como possibilidade de reflexão e retomada do caráter de contemplação, tremor e temor que deve estar presente numa experiência religiosa. Em outras palavras, considera a necessidade da revisão desses como instituições religiosas. Leora Batnitzky (2011) analisando judaísmo e modernidade aponta o importante papel de Rosenzweig e Martin Buber na ênfase e no compromisso com o retorno a uma vida judaica autêntica e destaca seus argumentos "Experiência, e não racionalidade, eles argumentam, é a base da vida judaica.” (p.73).

Consideremos agora outro aspecto. Mundo, Homem e Deus, estão presentes na história do pensamento filosófico como conceitos, no entanto, para Rosenzweig são elementos que vivenciam a experiência da relação. Do ponto de vista da temporalidade do novo pensamento, considera os tempos da Criação, da Revelação e da Redenção, os quais se relacionam e atualizam entre si. Temos aí a Estrela de Davi, símbolo do Judaísmo, com uma nova interpretação que tem como ponto de partida a relação que acontece no tempo. É importante tomarmos isso em conta para percebermos, a seguir, 
como ele se apropria do estabelecido pela tradição judaico-cristã e atualiza essas categorias em seu sistema filosófico.

Na temporalidade do novo pensamento não há linearidade e sim circularidade, Homem e Mundo atuam eficazmente, com vistas ao futuro, um sobre o outro, numa ação recíproca indissolúvel e apenas um terceiro pode redimi-los, Deus. Mas, a obra da criação e o ato da revelação atuam agora, autônoma e reciprocamente, como se ele não existisse; é um nome que homem e mundo irão levar em seu coração e será pelos seus atos, em comunidade, que se dirá dele que é bom. E todos são convidados a dar graças, o mundo inteiro, todos os pagãos e aqueles que temem a Deus.

Quando, no segundo volume da Estrela, Rosenzweig questionou sobre a possibilidade de viver o milagre, mostrou que o milagre é a vida que resiste sabendo que irá perecer, milagre é ter o instante que se nos é dado como que de uma fonte inesgotável, de um Deus que assim se revela e para o qual nos revelamos nós, criaturas, ao assumirmos, do ponto de vista ontológico, a nossa condição como seres mortais e, do ponto de vista ético, o amor ao próximo. A revelação traz a criação, porque no instante recordamos sempre o nosso passado, nossa ancestralidade, e antecipa a redenção, uma vez que, ao assumirmos a responsabilidade pelo outro hoje, voltamos nosso olhar para a descendência e tomamos consciência de que a redenção é o próprio ato de nosso amor que se produz hoje marcado pelo passado e com vistas ao futuro.

O amor ao próximo que supõe a entrega de si mas a cada momento a vence é a força que irrompe ao exterior desde as profundidades da alma, trazida pela vontade. Somente a alma amada faz de seu ato de amor no mundo mais do que um ato: o cumprimento de um mandamento de amor. E este cumprimento não é um ato isolado e sim uma série de atos, "O amor ao próximo está sempre brotando, é sempre um voltar a começar desde o começo; não há decepção que o confunda. Ao contrário, necessita decepções para não esmorecer, para não se enrijecer em ação organizada segundo esquemas, e seguir brotando como água viva." E se referirá a ele como um "completo trabalho de amor perdido no instante.” (ROSENZWEIG, 2006, p. 263).

Rosenzweig encerra o livro terceiro do segundo volume da Estrela apontando a Redenção como a eternização do milagre - a vida que vence a morte - compreendida não apenas como um depois, mas como "a paz sempre renovada que encontrou a alma solitária no amor de Deus”, (2006, p. 305), fazendo assim também da Redenção um acontecendo para aquele que ama o próximo. 
Imanência e transcendência em Franz Rosenžweig - 163 contribuições da Filosofia da Religião para as Ciências da Saúde

Acerca deste novo pensamento podemos ressaltar, numa tentativa de síntese do que afirmamos acima, que passamos da religião vista como resposta ou solução para a morte - como promessa de continuidade da vida e de recompensas - para a vida como um acontecendo, na qual a morte é companheira diária com quem aprendemos a conviver e assim assumimos a nossa condição no tempo da criação.

De outro lado, mais forte do que a morte é o amor, no tempo da revelação os homens seguem revelando seu amor na relação com o outro que se inicia quando reconhece esse outro como verdadeiramente outro e não um si mesmo. Assim, esse vencer a morte se dá num cotidiano sim à vida - própria e do outro, repetido diariamente, o que coloca a redenção como um acontecendo e não um depois.

O autor segue afirmando o lugar da experiência. Para ele, a verdade dá testemunho de si mesma, está no real e não traça divisões nele. A verdade não é Deus. Deus é a verdade, contudo, para ele, essa proposição não atinge a pretensão de alcançar o extremo do saber, ao contrário, se limita a reproduzir-nos com outras palavras aquilo em que mais intimamente confiamos em nossa experiência e que nos é familiar. Não se trata de um aparente saber acerca da essência e sim da experiência próxima e imediata de seu atuar. "Que Ele é a verdade não nos diz, em última instância, senão que Ele ama." (ROSENZWEIG, 2006, p. 456). O que significa dizer, como afirmamos anteriormente, que não podemos conhecer a Deus, o que temos é a experiência dos vínculos entre Mundo, Homem e Deus.

Pautado nas obras $O$ Novo Pensamento e $A$ Estrela da Redenção, Guinsburg sintetiza o pensamento desse autor afirmando que Deus não criou a religião e sim o mundo. A revelação não destrói o verdadeiro paganismo da criação, apenas lhe concede o milagre do retorno e da renovação. A revelação está sempre presente. O novo pensamento é pensamento judaico ou cristão, apenas porque e na medida em que estes renovam a "revelação concedida a Adão". O Judaísmo e o Cristianismo possuem uma posição em comum "mesmo depois de convertidos em religiões, encontram em si mesmos o impulso para ultrapassar a fixidez de uma instituição religiosa e de retornar ao campo aberto da realidade". E afirma "Em seu Deus, seu mundo e seu homem, pode expressar-se o segrêdo de Deus, do mundo e do homem, que sòmente pode ser experimentado, mas não expresso no curso da vida. Não sabemos o que "é" Deus, o que "ée" mundo e o que "é" homem. Sabemos apenas o que êles fazem ou o que lhes é feito." (1970, p. 517). 
Assim, considerando a pertença religiosa o que podemos conhecer é a realidade das relações expressa na individualidade, ou seja, não podemos conhecer um Deus judeu ou cristão, mas podemos conhecer o judeu e o cristão, e assim mundo e homem, porque há uma individualidade característica assumida a partir dessa confessionalidade. A reflexão rosenzweiguiana caminha para uma multidisciplinaridade, na medida em que considera a importância do diálogo entre a filosofia e a teologia "A relação verdadeira entre ambas disciplinas é fraternal em sua nova forma". (2005, p. 37).

Considerando a possibilidade da não pertença e mesmo de não haver fé, no novo pensamento há dois elementos que nos remetem para fora de nós mesmos ou, dito de outra maneira, retira o Homem da centralidade que são a morte, a qual se impõe como parte da nossa condição, com a qual precisamos aprender a conviver em direção à vida e o tempo sobre o qual não temos nenhum domínio, que nos vem no instante que nos é dado e tirado sem prévio aviso.

Assumir a criação é assumir essa falta de controle acerca daquilo que nos é mais caro, ou seja, o tempo de nossa vida. Essa revelação de que o nosso tempo pertence a um outro, nos é feita pelo próprio tempo e pelo outro com quem nos relacionamos, do que decorre ser a redenção um acontecendo, em outras palavras, as relações estabelecidas entre os Homens no Mundo, se permeada do amor pelo próximo, podem redimir criando e revelando o tempo sempre novo da vida.

\section{Um novo pensamento para uma Filosofia das Ciências da Saúde}

Hans Jonas (1903-1993), considerando uma filosofia da biologia, chegou ao seu Princípio Responsabilidade em que trata de uma ética possível para o século XXI, sobretudo, no campo da biotecnologia, no qual o homem é objeto de estudo do próprio homem. Para ele, a medicina - porque ciência e arte - é o lugar da aplicabilidade deste princípio. ${ }^{2} \mathrm{Da}$ mesma forma, podemos pensar acerca das contribuições do novo pensamento de Franz Rosenzweig para a fundamentação de uma filosofia das ciências da saúde, passível de ser aplicada no campo da atenção e da assistência.

Para tanto, consideraremos o seu Livrinho, que faz uso de uma

Conforme o prefácio do próprio autor, a obra Técnica, Medicina e Ética (1985) cumpre o papel de ilustrar as questões trazidas em seu O princípio responsabilidade (1979) acerca temática ética e tecnologia. 
Imanência e transcendência em Franz Rosenžweig - 165 contribuições da Filosofia da Religião para as Ciências da Saúde

metáfora justamente no campo da saúde, conjuntamente com $A$ Estrela, a fim de evidenciarmos as possibilidades desse novo pensamento, como fundamento tanto para a especificidade de uma filosofia para as ciências da saúde, quanto para a imbricação entre espiritualidade e saúde, que acontece na prática do cuidado e da assistência nessa área.

A metáfora é sobre um doente; sua doença - apoplexia philosophica aguda, um ataque de paralisia que acontece ao homem por insistir na pergunta acerca do que as coisas são, que o retira da vida; o diagnóstico; o acompanhamento médico; o tratamento e o processo de cura; a convalescência e, finalmente, o retorno ao trabalho.

No Livrinho, Rosenzweig aponta a necessidade de uma filosofia capaz de tomar em conta a experiência de seres humanos concretos, que considere suas contingências e as relações que estabelecem entre si, com o Mundo e com Deus, em outras palavras, a realidade - a qual, consequentemente, não é uma criação do sujeito. Para não paralisar diante do que nos assombra é preciso não pensar sobre isto, é preciso seguir vivendo.

As ciências da saúde são igualmente as ciências da vida. Vivem o desafio, imposto por sua multiplicidade, de por um lado, se ocuparem com o pensar, na pesquisa e no desenvolvimento de novas tecnologias, remédios e soluções, e de por outro, lidarem com as questões subjetivas ligadas ao cuidado e à assistência. A seguir, consideramos alguns temas trazidos pela metáfora, ilustrando, por assim dizer, possibilidades de reflexão específicas ao âmbito da saúde e mesmo da educação em saúde:

A morte - É sempre muito difícil entender a morte e, ainda mais, nas ciências e nas formas de assistência que se deparam direta e constantemente com ela. Rosenzweig afirma "O vivente cai estupefato diante da morte. E um dia ele mesmo morre. Seu assombro está resolvido. A própria vida trouxe essa solução." (2001, p. 14). Em outras palavras, o homem comum (aquele que aceita a vida como ela é) não paralisa diante da possibilidade da morte, a reconhece como parte da vida. A morte é um acontecimento que desafia a vida a viver bem, sabedora de sua finitude.

Contra a morte não há remédio. Tampouco a saúde é um remédio. Porém o são tem força para andar no caminho que conduz à tumba pleno de vida. $\mathrm{O}$ enfermo chama a morte e se deixa carregar por ela em suas costas, meio morto de angústia mortal. A saúde vive a morte somente "a seu devido tempo", e é muito amiga dela e sabe que, quando chega, tira sua máscara rígida e à angustiada, fatigada, decepcionada irmã vida lhe tira a tocha flamejante 
de suas mãos cansadas, joga-a no chão e a apaga, e sob a abóbada do céu noturno, que só agora brilha depois de extinguir-se o resplendor da tocha, toma aquela que está falecendo em seus braços e, uma vez que a vida cerrou os lábios eloqüentes, abre sua eternamente calada boca e diz: Me reconheces? Sou sua irmã. (2001, p. 94).

A morte aqui é empiria. Considerando os fundamentos para uma filosofia das ciências da saúde, a certeza de nossa finitude e o reconhecimento dos limites que isso impõe são antídotos para as pretensões do Homem moderno que reduz Deus e o Mundo ao Eu, lugar da autossuficiência, da onipotência, do ego. É reconhecendo a finitude e, consequentemente, os limites e a possibilidade do fracasso que se pode continuar andando, sem paralisar, quando acontecem os encontros rápidos, significativos, fortes entre o Mundo, o Homem e Deus. Nas ciências da saúde é preciso, e urgente, considerar a morte, o que não significa deixar de fazer o possível pela vida, mas sim a necessidade de admiti-la como parte da vida e isso pode mudar muito, inclusive e por exemplo, nas questões ligadas à Bioética.

Considerando uma filosofia para seres humanos reais, reconhecer que é com a compreensão da morte que podemos chegar à Vida, esse é o caminho da Estrela, que se inicia com a morte. É preciso curar-se do medo da morte. O homem sábio sabe que vai morrer e deixa que a morte caminhe ao seu lado e por isso é capaz da ação no tempo, no instante. É capaz de reconhecer que esse instante lhe é gratuito, é a sua sempre eternidade, é o lugar da possibilidade. É no instante que lhe é dado que o Homem pode escolher relacionar-se com o Mundo, com Deus e decidir-se por sua criaturalidade, reconhecendo a si mesmo como criatura insuficiente. É no reconhecimento da insuficiência que tem lugar o outro, tornando possível as relações.

O tempo - É preciso saber esperar, saber seguir vivendo, mas o filósofo (ou o cientista, o médico, o enfermeiro ou cada um de nós) não quer esperar, a solução tarda, quer a solução hoje, aqui e agora e então fica paralisado, pretendendo saber o que as coisas são, independentemente do tempo, retirando-se do curso da vida. A palavra da vida não é o propriamente e sim o realmente. O real é o que verdadeiramente acontece ao homem e só a ele, no tempo, daí a necessidade da compreensão do tempo como fundamento das ciências da saúde. Inclusive porque diante da dor, do sofrimento e da morte o tempo é outro. É comum que aquele que está doente manifeste o seu mal estar com o tempo, que para ele não passa, ou passa lentamente por conta da enfermidade que o retirou do fluxo de sua vida. 
Imanência e transcendência em Franz Rosenžweig - 167 contribuições da Filosofia da Religião para as Ciências da Saúde

Somente é possível conhecer no tempo, inclusive as coisas últimas e supremas. Conhecer a Deus, ao Mundo e ao Homem significa conhecer o que eles fazem nos tempos da realidade, o que fazem e o que lhes acontece é a experiência de seus vínculos. Tais experiências acontecem no tempo, consequentemente, uma filosofia para seres humanos reais necessita considerar o tempo, no qual se dão as experiências advindas das relações.

A ciência - Rosenzweig faz a mesma crítica à ciência, à filosofia e à teologia, quando tentam entender e explicitar o Mundo buscando compreendê-lo em sua totalidade de maneira infinitamente pretensiosa e infinitamente modesta ao mesmo tempo,

Se contenta em somente mostrar um novo raio, até então não observado, que brilha de um ponto a outro, ou em produzir esse raio mediante um novo agrupamento engenhoso dos pontos, ou seja, se contenta no dia a dia, mas somente se daria por satisfeita de haver registrado de maneira exaustiva a totalidade de todos esses reflexos e contrareflexos infinitamente possíveis, ou seja, nunca. (ROSENZWEIG, 2001, p. 51).

O novo pensamento possibilita uma nova cosmovisão e, conseqüentemente, uma nova compreensão do conhecimento, a qual supõe o cuidado para não reduzirmos - risco de toda ciência - esse conhecimento. Essa não redução consiste em considerá-lo, tendo como ponto de partida a experiência e o diálogo. O real não é aquilo que a ciência, a filosofia ou a teologia apresentam separadamente, é mais do que isso e exige, portanto, uma abordagem multidisciplinar capaz de considerar a multiplicidade.

Para tanto, é preciso aprender com o senso comum são que se conforma com a estabilidade dos nomes, ou palavras, nomes próprios ou designações, e concede às coisas, às vivências e aos acontecimentos sua liberdade indubitável, enquanto o enfermo entende os nomes como sem valor [quer a essência] e retém as coisas, vivências e acontecimentos para perguntar-lhes pelo que são.

Por último, há ainda o pensar equivocado, baseado nos livros. Quando se busca algo atrás do real e se quer que seja o real. Aqui se confundem o real e ideal e ambos se transformam em "ismos", no sentido da redução. Não há reconciliação entre o fazer e o pensar: real-ismos e ideal-ismos. Aqui a cura é pelo acontecimento, pelo acontecendo, pelo transcurso mesmo da vida. Será preciso vencer as "perguntas últimas", ou seja, a pergunta pelo Mundo, pelo Homem e por Deus, para poder perceber que "São estas três cordilheiras 
antiquíssimas por entre as quais discorrem as vias da vida. É algo natural que, em alguma ocasião, uma das voltas do caminho abra a perspectiva até uma destas cordilheiras. E quem acreditar que tem que se deter aqui, está perdido. (ROSENZWEIG, 2001, P. 37).

Do ponto de vista epistemológico, uma filosofia das ciências da saúde necessita deparar-se com os grandes temas que se relacionam com a vida. Da mesma forma como afirmou Georges Canguilhem (2009) acerca da relatividade do conceito de saúde, posto pensarmos nela justamente quando não a temos, na área da saúde alguns dos temas que nos convocam são a dor, o sofrimento e a morte, exceção feita, por exemplo, quando nos referimos às práticas preventivas em saúde, muito embora, a bem da verdade, também nestes momentos necessitem ser considerados.

Daí a contribuição do pensamento rosenzweiguiano para a especificidade dessa filosofia. Destacamos aqui três tópicos. A consideração da morte, impõe um outro pensar e outro fazer às ciências da saúde e suas práticas; a consideração do tempo e, em seu bojo, das relações aponta a necessidade de considerar a singularidade, a experiência para nos aproximarmos do real e, finalmente, o pensar acerca da ciência destaca a realidade e a necessidade da multiplicidade de olhares para dela nos aproximarmos.

Jacqueline Lagrée (2002), no capítulo em que trata das virtudes necessárias ao doente e ao médico para que estabeleçam uma relação afirma o valor da experiência "quem atravessou a prova da doença, a sua ou a de uma pessoa próxima, compreenderá quanto isso reaviva o desejo de viver bem, de viver de uma forma verdadeira e feliz." E mais adiante: “A eternidade não é mais a perpetuação ilimitada do tempo nem a sua suspensão, mas antes o presente cumprido, a necessidade assumida e compreendida.” (p. 190).

\section{Espiritualidade no cuidado e na assistência em saúde - A metáfora na vida}

Ao contrário de deter-se diante do Mundo, do Homem e de Deus, ou pelo assombro ou por desejar entender suas essências, é preciso tomar o Homem integralmente, considerando todas as suas experiências nas suas relações com o Mundo, com Deus e com os outros Homens e esse é o caminho para a cura.

Para Rosenzweig, ainda que o Homem tenda a buscar pela essência, por uma racionalidade capaz de explicar a totalidade, o tráfego terreno consegue se impor pelo poder dos acontecimentos do dia a dia, das pequenas tarefas a 
Imanência e transcendência em Franz Rosenžweig - 169 contribuições da Filosofia da Religião para as Ciências da Saúde

serem realizadas e dos nomes que permanecem, sendo assim, a vida mesma pode curá-lo por um único e forte acontecimento - um choque, como uma doença grave, a morte de alguém querido, a proximidade pessoal da morte, mas nada disso pode ser provocado, ao contrário, essas situações provocam "A revolução contra os firmes nomes transmitidos por tradição se apaga, cessa a busca de um sentido oculto atrás dos acontecimentos, se tomam os acontecimentos como vividos e não se lhes busca outro sentido que os próprios nomes".

Anteriormente, afirmamos que se existe um lugar onde a relação entre o ser humano e a transcendência acontece, esse é exatamente o lugar da falta, da ausência da saúde, quando a dor e o sofrimento, causados pela doença e pela percepção concreta de nossa humanidade - caracterizada pela certeza da morte - se instalam e se sobrepõe o doloroso sentimento de impotência frente a essa inevitável experiência. Esse é o lugar da cura por um choque, no qual, todos nós, acostumados a não pensar e mesmo não olhar para a morte, somos obrigados pela própria vida a olhar de frente para ela.

Essa é uma experiência cotidiana na vida de quem está à frente da saúde, no cuidado e assistência, em que é possível constatar que diante da doença e da morte; da experiencia da fragilidade; da vulnerabilidade têm lugar as experiências ligadas à espiritualidade e, por essa razão, dissemos tornar-se necessário um pensamento não excludente, que considere todas as contingências que nos tornam exatamente quem somos. Anteriormente, consideramos uma filosofia da religião entendida como possibilidade de diálogo entre a razão, como a entendemos filosoficamente, e a razão religiosa, o pensamento que resulta de experiências religiosas. Aqui consideraremos, a partir do Livrinho, as possíveis contribuições desse pensamento para a compreensão do binômio Espiritualidade e Saúde.

Deus - Um dos três elementos em relação com o Mundo e o Homem. No livro terceiro da Estrela, no qual tratará da eternidade da verdade, Rosenzweig evidencia que a muda escuridão do antemundo adquire linguagem na morte. E mais forte do que a morte é o amor. O amor se resolve pela vida e a vida se concentra no silêncio do supramundo e se transforma em luz, assim, Deus não é vida e sim luz. É senhor da vida mas não está vivo nem morto. Deus infunde vida ao morto. E é Deus dos vivos e dos mortos precisamente por não estar nem vivo nem morto.

Dele o que temos é a experiência. "Experimentamos sua existência de maneira imediata unicamente em que nos ama e desperta nosso morto 
si-mesmo fazendo da alma amada e que responde ao amor com amor. A revelação do amor divino é o coração do Todo. Que Deus ama é o que experimentamos, não que Deus é o amor." (2006, p. 449). Deus é uma realidade entre outras, está em relação com o Mundo e com o Homem. Cada Homem, na concretude de sua experiência, se aproximará dele de uma forma e dessa aproximação resultará um entendimento e uma ação, daí a vastidão da compreensão da espiritualidade.

A terceira semana de cura diz respeito a Deus. Rosenzweig considera a metafísica como a primeira ciência de Deus e vê no ateísmo uma importante contribuição para se avançar em relação à pretensão filosófica e teológica de entendê-lo e explicá-lo, assumindo que não há nada a pensar a seu respeito, não se trata nem de essência. Também não há nada a fazer com Deus, não se trata de aparência. A natureza, por exemplo, também não é Deus, ela é o Mundo. Para ele, crer não deveria exigir novos nomes. Se alguém pensa que necessita descobrir a verdadeira intenção, o verdadeiro conteúdo por trás das coisas em que diz acreditar, então não crê nelas. Em ambos os casos, não temos a relação entre Homem - Mundo - Deus, não temos Deus.

Para Rosenzweig importa a relação e a ação, assim o Homem tem o instante, tudo o mais, seja Deus ou o Mundo, na relação o ajudam a viver o instante. E nele, ele tem tudo, pode cumprir o mandamento que lhe é dado pois, foi dado para o instante e sempre somente para o instante. Aquele que em cada ocasião é o seu próximo, o instante que cada vez é o próximo podem representar toda a eternidade das coisas. No instante que se dão as pontes entre Deus - Homem - Mundo.

Deus não tem nome para ser chamado, o nome de Deus muda para "ser encontrado por toda a terra, de um homem a outro homem, de coisa a coisa, de povo a povo, de uma ordem a outra". O nome de Deus é dupla causa do mundo e dos homens em marcha, flui com ambos em nome e palavra ao mesmo tempo. O nome vem do homem e a palavra do mundo, Deus é do homem e do mundo. (ROSENZWEIG, 2001, p. 81).

Deus é a Verdade e está fora de nós. É chamado para se incorporar na comunidade que chama, não se trata de um Deus de cada um. Ao homem cabe confiar naquele que deixou vir a vida a esse mundo, o momento oportuno é o hoje, tem que confiar em Deus queira ou não: "Desejarias que antes te provassem teu hoje e teu aqui, a partir de razões profundíssimas e desde uma essência eterna? Ai de ti se então ainda o pedes! Porém não 
Imanência e transcendência em Franz Rosenz̧weig - 171 contribuições da Filosofia da Religião para as Ciências da Saúde

podes mais pedir. Inclusive tu não tem mais tempo para pedi-lo. É chegado o tempo oportuno (fazer). E Deus te ajudará.” (ROSENZWEIG, 2001, p. 84).

Como dissemos, Mundo, Homem e Deus são três elementos distintos e o conhecimento que deles podemos ter é a partir de sua relação nos tempos da criação, da revelação e da redenção. Assumir a criação como si mesma, sem a perspectiva do tempo, coloca em destaque a perspectiva da fé, necessária para que o Homem e o Mundo se reconheçam como criatura, mas não necessariamente a forma para que sejam capazes de criaturalidade.

Essa criaturalidade, por sua vez, tendo origem nos próprios elementos, Homem e Mundo, somente terá consistência numa realidade efetivamente experimentada, ou seja, Homem e Mundo experimentam seus limites, as relações que estabelecem para ultrapassá-los e assim vão reconhecendo vai acontecendo - sua criaturalidade que vivencia a revelação no instante e a redenção no compromisso para com o outro diferente de si mesmo, um tu.

$\mathrm{O}$ homem vive no mundo o instante e esse é, objetivamente, todo o tempo de que realmente dispõe e sabe que vai morrer. A morte se coloca como a grande experiência do limite. Quando, diante disso, o homem se fecha em si mesmo temos a experiência da paralisia, do medo e muitos encontram na espiritualidade a possibilidade de não paralisarem, ao contrário, seguirem em frente ao terem a coragem de voltar-se para essa experiência.

O próximo - O mais próximo é apenas representante, o amor não lhe é destinado unicamente, no instante fugaz em que o amor é presente recai sobre todo o conjunto - homens e coisas - o mundo, inacabado e em devir, não essência e não mera existência, mas a vida. A natureza orgânica é um signo visível de um conceito de vida que estende seus domínios para além de suas fronteiras. O conhecimento deles só é possível no tempo, para eles há um futuro: a redenção que lhes chega na sucessão de instantes.

$\mathrm{Na}$ lógica da redenção Deus é um porque redime a si mesmo; o reino de Deus impregna o Reino do Mundo no amor ao próximo. O que deve o homem é amar o próximo como a si mesmo, teu próximo é como tu. $\mathrm{O}$ homem não deve renegar a si.

É na Análise gramatical do Salmo 115 que Rosenzweig evidencia que o que podemos dizer de Deus diz respeito à sua proximidade e à sua distância do homem e do mundo. O Salmo é um "nós" enfático num "dar". Se pede pela vinda do reino e se louva ao Senhor enquanto se vive esse nós que é doação e, assim, se antecipa a redenção e se louva a eternidade na presença de cada novo instante que faz com que sejamos eternos: "Nós somos eternos: 
ante este grito de triunfo da eternidade, a morte cai em nada. A vida se faz imortal no eterno canto de louvor da redenção”. (2006, pp. 303-305).

Como fazer com que esse amor se efetive na prática, é o que ocupará Rosenzweig no terceiro volume da Estrela. Há uma nova relação entre o tempo e a vida eterna expressa no que chamou de instante eterno, que chama o homem à ação, se transformando em horas da vida humana e que se realiza na comunidade dos homens. A Redenção não é obra nem ato de Deus. Ele deu força para a criação crescer plena de vida e liberou em seu amor a alma para a liberdade a ação de amor. Essa liberdade é querida por Deus e está expressa no mandamento do amor ao próximo.

Para Rosenzweig, o amor fecha a perspectiva do olhar quando o próximo representa o mundo inteiro, porém a oração, ao pedir iluminação, vê e libera o amor da atadura das mãos e lhe ensina a buscar seu próximo com os olhos, fundando assim a ordem humana do mundo. "Esta é a desgraça do amor ao próximo distante: ainda que realize um autêntico ato de amor, morre na meta que alcançou, exatamente igual ao que acontece à ação com vistas a um fim." (2006, p. 326).

O tempo e a hora são tanto mais poderosos quanto menos o homem os conhece. Deus não necessita do tempo, quem dele precisa são o homem e o mundo. Considerado o amor, o elemento fundamental da liturgia não é a palavra e sim o gesto. Da Estrela o que se pode ver é o seu brilho, ela não fala, é como um rosto que é eloquente sem que os lábios se abram. A linguagem comum, em meio à pluralidade de línguas, é o gesto comum.

E no que diz respeito aos crentes e não crentes "A quem a invoca (a verdade divina) com a dupla oração do crente e do incrédulo, a esse não lhe negará. Deus dá de sua sabedoria tanto a uma como a outra, a fé como a não crença; mas a ambas somente quando sua oração chega a ele unida." E continua "O mesmo homem é o que vem com uma súplica dupla e ele há de entrar em sua presença com uma dupla gratuidade por ser ao mesmo tempo um incrédulo filho do mundo e um crente filho de Deus, que presenteia com sua sabedoria tanto à carne e ao sangue como aos que o temem. (ROSENZWEIG, 2006, pp. 252-253).

A saudação de todos a todos tem como pressupostos a escuta e a comida em comum e isso só pode acontecer na comunidade em que cada um conhece a todos e os saúda sem palavras: cara a cara. A fraternidade é o laço que vincula os indivíduos na diferença: 
Imanência e transcendência em Franz Rosenžweig - 173 contribuições da Filosofia da Religião para as Ciências da Saúde

Amarra, pois, a fraternidade seu laço entre os homens que não se parecem uns com os outros. De nenhuma maneira é ela a igualdade de todos os rostos humanos, e sim a concordância entre homens dos mais diversos rostos. $\mathrm{O}$ que é necessário é que os homens tenham, em geral, rosto: que se vejam uns aos outros. A igreja é a comunidade de todos os que se vêem mutuamente. Une os homens como contemporâneos [...]. (ROSENZWEIG, 2006, p. 409).

Para o autor, o homem de verdade, pleno é aquele do qual de sua resposta nasce a palavra e sua espera de Deus é marcha diante de um Deus que se revela. Ao abrir-se até ser pleno o homem se torna visível e audível, capaz do diálogo e de entrar nos sentimentos de seu interlocutor, não porque lhe impõe medo ou compaixão, mas pela contradição e cumplicidade. Sua visão de mundo e do seu próprio lugar se dá a partir de uma perspectiva determinada: do eu singular e próprio que reconhece sua existência trágica que transcorre em atos e padecimentos, carente de consciência, a não ser a de seus próprios limites.

As religiões - analisando as implicações do pensamento de Rosenzweig para o cristianismo e o judaísmo, Bernhard Casper lembra que para ele a revelação é um acontecer acontecendo que nasce de Deus e esse acontecer se origina no dizer, o que, em si, já mostra a necessidade do outro e de tomar a sério o tempo inaugurando um diálogo novo entre ambos:

No reconhecimento dessa indigência e desta necessidade, mediante a qual eu confesso não ser o todo, mas apenas sou o que sou, de forma mortal e temporal, reside já para Rosenzweig uma confissão da unicidade de Deus. E precisamente por causa desta confissão, com a qual o sujeito confessa não ser o todo, deve voltar-se a um dizer-novo da Verdade na história, o qual, segundo a dimensão da verdade que apela à vida, exige um novo compromisso vital, um novo testemunho. (CASPER, 2006, p. 776).

Harold Koenig (2015) considera a espiritualidade e a religião como aspectos da experiência humana a serem considerados na saúde. Para ele, o termo religião é mais preciso para ser usado em pesquisa, enquanto o termo espiritualidade, por sua abrangência, seja mais bem utilizado em ambientes clínicos quando os médicos querem ser sensíveis à variedade de crenças das pessoas.

Para ele, caso se tenha a intenção de fazer pesquisa considerando a espiritualidade, o pesquisador deve, a priori, apontar sua compreensão do termo. No cuidado e na assistência em saúde, as questões ligadas às religiões 
ou à espiritualidade aparecem muito e, certamente, com mais força onde a vida corre risco, em situações nas quais não há um prognóstico de cura.

Disso decorre a importância de um referencial para tratarmos de um assunto tão importante para a vida das pessoas. Aqui a contribuição do novo pensamento vem tanto no sentido de diferenciar a instituição e a experiência religiosas, a fim de capturar a realidade da experiência singular do Homem; quanto na ampliação da compreensão acerca de Deus e do Homem em relação.

\section{Considerações finais}

Entendemos que o novo pensamento de Franz Rosenzweig amplia nossas possibilidades de tomarmos em conta a realidade - e não apenas o que pensamos sobre ela, isto porque considera o movimento produzido pelas relações, do que decorre uma compreensão diferenciada da imanência e da transcendência, as quais, agora, se definem como aproximação e distanciamento entre as três potências Mundo, Homem e Deus no tempo. Esta experiência que se dá no tempo é a nossa existência.

Essa perspectiva relacional coloca o novo pensamento em posição diametralmente oposta ao pensamento preponderante na modernidade, no qual há a centralidade do Homem. A relação só pode acontecer no movimento de saída de si em direção a um outro que fala e, exatamente por essa razão é um outro, do que decorre a perspectiva dialógica do pensamento de Rosenzweig que tem como premissas que somente podemos ser questionados por pessoas e que a possibilidade do diálogo se abre no tempo da pergunta de um e da resposta do outro.

Sendo a transcendência esse movimento de sair de si em direção ao outro, esse novo pensamento retira o foco de Deus e das religiões em si, uma vez que importam as relações entre os Homens e deles com o Mundo e com Deus. Nas ciências da saúde podemos considerar aquilo que é trazido pelas grandes tradições religiosas, como experiências humanas, acerca da compreensão da dor, do sofrimento e da morte. Quando a modernidade interdita o diálogo entre o saber das tradições religiosas e o saber das ciências, em verdade, interdita o próprio Homem.

A temporalidade do novo pensamento também nos importa considerar. O Homem tem o instante e quando não o tem, perece. Essa aceitação da radicalidade do tempo pode ser um grande contributo para uma filosofia das ciências da saúde e suas práticas, sendo que também aqui podemos contar com as tradições religiosas que se dão conta dessa radicalidade. 
Imanência e transcendência em Franz Rosenz̨weig - 175 contribuições da Filosofia da Religião para as Ciências da Saúde

Rosenzweig assim afirma essa temporalidade "Para um médico que está tratando um caso, o tratamento é o presente, a enfermidade é o passado e a constatação da morte é o futuro" e complementa "não teria nenhum sentido que ele, para obedecer a um tic do conhecimento atemporal, quisesse excluir do diagnóstico o saber e a experiência, da terapia a audácia e a obstinação, do prognóstico o temor e a esperança." (2005, p. 31).

\section{Referências}

BATNITZKY, Leora F. How Judaism became a religion: an introduction to modern jewish thought. Princeton: Princeton University Press, 2011.

BENJAMIN, Walter. O Narrador - Considerações sobre a obra de Nikolai Laskov. Magia e técnica, arte e política - ensaios sobre literatura e história da cultura. São Paulo: Editora Brasiliense, 1985. 197-221

BOURETZ, Pierre. Testemunhas do futuro: filosofia e messianismo. São Paulo: Perspectiva, 2011.

CÂNDIDO, Viviane Cristina. Franz Rosenzweig e a Educação: Conhecimento na diferença, tendo a tensão como método. In: ROSIN, Nilva; SANTOS, Robinson dos. (Orgs). Filosofia e política em Franz Rosenzweig. Passo Fundo: IFIBE, 2010. p. 143-170

- Beleza e Espiritualidade em Franz Rosenzweig: Uma contribuição para o estudo da estética na Estrella de la Redención. INTERAÇÕES - Cultura e Comunidade, v. 7, n. 12, p. 143-163, jul./dez, 2012 Disponível em: http://periodicos.pucminas.br/index.php/interacoes/ issue/view/360. Acesso em 18/05/2019

O mal em Machado de Assis. Cristianismo versus Condição Humana: As Memórias Póstumas de Brás Cubas na perspectiva da Filosofia da Religião e da Educação. São Paulo: Musa Editora, 2011.

CASPER, Bernhard. Franz Rosenzweig: Desafio para um novo Futuro, pp. 769-784. In: VILA-CHÃ, João J. (Ed.). Entre Razão e Revelação: A 'Lógica' da Dimensão Semítica na Filosofia. Braga: Revista Portuguesa de Filosofia, 2006, v. 1, 686pp.

CANGUILHEM, Georges. O normal e o patológico. Rio de Janeiro: Forense Universitária, $6^{\mathrm{a}}$ ed. rev., 2009.

GUINSBURG, J. (org.) O judeu e a modernidade: Súmula do Pensamento Judeu. São Paulo: Editora Perspectiva, 1970.

JONAS, Hans. O princípio vida: fundamentos para uma biologia filosófica. Petrópolis, RJ: Vozes, 2004.

O princípio responsabilidade: ensaio de uma ética para a civilização tecnológica. Rio de Janeiro: Contraponto: Ed. PUC-Rio, 2006.

- Técnica, Medicina e Ética - sobre a prática do princípio responsabilidade. São Paulo: Paulus, 2013. 
KOENIG, Harold G. Medicina, religião e saúde - o encontro da ciência e da espiritualidade. Porto Alegre: L\&PM, 2015.

LAGRÉE, Jacqueline. O médico, o doente e o filósofo. Coimbra: Gráfica de Coimbra, 2002. MATE, Reyes. Renacimiento del pensamiento judio em el siglo XX, p. 409-431. In: VILACHÃ, João J. (Ed.). Entre Razão e Revelação: A 'Lógica' da Dimensão Semítica na Filosofia. Braga: Revista Portuguesa de Filosofia, 2006, v. 1, 686pp.

ROSENZWEIG, Franz. Understanding The Sick \& The Healthy - A View of World, Man, and God. Harvard University Press, 1999

El libro del sentido común sano y enfermo. Madrid: Caparrós Editores, 2a . ed., 2001. . The Star of Redemption. Notre Dame: University of Notre Dame Press, 2002.

. El Nuevo Pensamiento. Buenos Aires: Adriana Hidalgo Editora, 2005.

__. La Estrella de la Redención. Salamanca: Ediciones Sígueme, 2006.

_. Hegel e o Estado. Tradução Ricardo Timm de Souza. São Paulo: Perspectiva, 2008.

SHELLEY, Mary. Frankenstein. São Paulo: Editora Landmark, 2016.

SMITH, Barbara Herrnstein. Crença e Resistência: a dinâmica da controvérsia intelectual contemporânea. Trad. Maria Elisa Marchini Sayeg. São Paulo: Editora UNESP, 2002.

Submetido em: 20-6-2020

Aceito em: 28-8-2020 